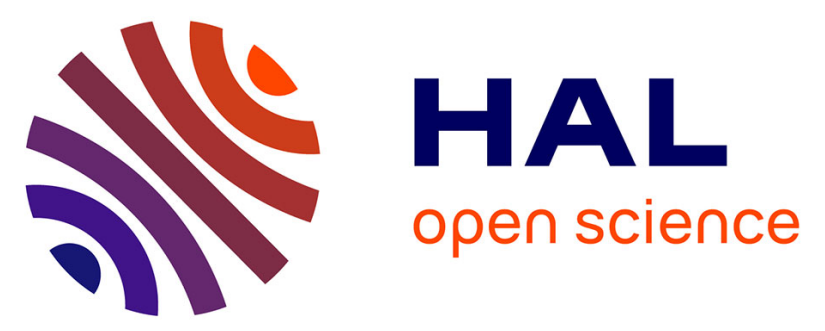

\title{
Exploiting Local Facilities for Post-Pulmonary Rehabilitation Maintenance Programs in Fibrotic Idiopathic Interstitial Pneumonia Patients: A Pilot Study
}

Baptiste Chéhère, Jean-Marie Grosbois, Cécile Chenivesse, Benoit Wallaert, Valerie Bougault

\section{To cite this version:}

Baptiste Chéhère, Jean-Marie Grosbois, Cécile Chenivesse, Benoit Wallaert, Valerie Bougault. Exploiting Local Facilities for Post-Pulmonary Rehabilitation Maintenance Programs in Fibrotic Idiopathic Interstitial Pneumonia Patients: A Pilot Study. Respiratory Medicine and Research, 2019, 76, pp.3. 10.1016/j.resmer.2019.07.006 . hal-02557268

\section{HAL Id: hal-02557268 \\ https://hal.univ-cotedazur.fr/hal-02557268}

Submitted on 28 Apr 2020

HAL is a multi-disciplinary open access archive for the deposit and dissemination of scientific research documents, whether they are published or not. The documents may come from teaching and research institutions in France or abroad, or from public or private research centers.
L'archive ouverte pluridisciplinaire HAL, est destinée au dépôt et à la diffusion de documents scientifiques de niveau recherche, publiés ou non, émanant des établissements d'enseignement et de recherche français ou étrangers, des laboratoires publics ou privés.

$$
\text { Copyright }
$$


Title: Exploiting local facilities for post-pulmonary rehabilitation maintenance programs in fibrotic idiopathic interstitial pneumonia patients: A pilot study.

Authors: Baptiste Chéhère ${ }^{\mathrm{a}, \mathrm{b}}$, Jean-Marie Grosbois ${ }^{\mathrm{c}, \mathrm{d}}$, Cécile Chenivesse ${ }^{\mathrm{e}}$, Benoit Wallaert ${ }^{\mathrm{d}, \mathrm{e}}$ and Valérie Bougault ${ }^{\mathrm{a}}$.

\section{Affiliations:}

${ }^{a}$ University of Lille, EA 7369 - URePSSS - Multidisciplinary Research Unit in Sport Health Society, F-59000 Lille, France (baptiste.chehere@univbrest.fr/vbougault@unice.fr). $\quad{ }^{b}$ Univ Brest, ORPHY, F-29200 Brest, France (baptiste.chehere@univ-brest.fr)._ $\quad{ }^{\mathrm{c}}$ FormAction $\quad$ Santé, Pérenchies, France (jmgrosbois@formactionsante.com). ${ }^{\mathrm{d}}$ Department of Respiratory Medicine, Centre Hospitalier Germon et Gauthier, Béthune, France (jmgrosbois@formactionsante.com/bwallaert@gmail.com). ${ }^{\mathrm{e}} \mathrm{CHU}$ Lille, Department of Immuno-Allergology and Respiratory Diseases, Competence Centre for Rare Pulmonary Diseases, University of Lille, F-59000 Lille, France (cecile.chenivesse@chrulille.fr/bwallaert@gmail.com). ${ }^{\mathrm{f}}$ LAMHESS, Université Côte d'Azur, Nice, France (valerie.bougault@unice.fr)

Corresponding author: Baptiste Chéhère, $\mathrm{PhD}$

EA4324 - Optimisation des Régulations Physiologiques (ORPhy)

20 Avenue Le Gorgeu CS 93837, 29238 Brest Cedex 3, FRANCE

Phone: +33608320762, Fax: +33298017147,E-mail: baptiste.chehere@univ-brest.fr

Declarations of interest: None

Funding: Funding was provided by the Multidisciplinary Research Unit in Sport Health Society (URePSSS, Lille, France). 
We previously reported the results of an 8-week home-based pulmonary rehabilitation (PR) program in patients with fibrotic interstitial idiopathic pneumonia (f-IIP), which demonstrated significant long-term (12 month) improvements in exercise capacity, anxiety, and quality of life [1]. However, most studies of f-IIP patients have shown that the benefits are lost within 6 to 9 months after the PR program [2], largely due to a failure to continue with exercise training [3]. Indeed, previous studies did not offer maintenance program after PR [2]. Therefore, it is important to identify simple and effective ways through which patients can maintain a post-PR exercise program and sustain their improvements in physical and psychological outcomes. To this end, we compared the effectiveness of two post-PR maintenance programs suggested to f-IIP patients: unsupervised self-selected exercise at home or a structured exercise at a local facility (e.g., fitness center, pool) close to the patient's home.

Twenty-one patients with mild to moderate f-IIP who included the home-based 8week supervised PR program, as previously described [1, 4], were recruited to this pilot study, and 19 completed it (Figure 1). Before the end of PR, subjects voluntarily chose the maintenance program format: an adapted physical activity (APA) program structured at local facilities (APA group) or our routine program proposal offering exercises to achieve autonomy in the patient's home (control group). The activities were tailored to each patient's physical capacity and preference (Figure 1) and the local facilities had to be easily reachable by public transport if necessary. Approval for the data use was obtained from the Institutional Review Board of the French Learned Society for Pulmonology (CEPRO 2017-007). Written informed consent was obtained from each participant.

Before and immediately after the 8-week PR program [1] and 6 months after initiation of the maintenance program, subjects in both groups were assessed for: pulmonary function, exercise capacity (6-minute walk test [6MWT] and stepper test [6MST]), quality of life 
(Medical Outcomes Study SF-36), dyspnea (baseline/transition dyspnea index), and physical activity motivation (Behavioural Regulation and Exercise Questionnaire 2) [5]. Data were analyzed using SigmaStat (version 3.5). Univariate normality assumptions were verified with the Kolmogorov-Smirnov test. Changes in parameters with time were assessed with one-way repeated measures ANOVA, and group differences in baseline parameters and their distribution were assessed with an unpaired t-test and Fisher's test, respectively. $\mathrm{P}<0.05$ was considered statistically significant.

Of the 19 patients who completed the 6-month maintenance program, 12 and 7 had idiopathic pulmonary fibrosis and fibrotic nonspecific interstitial pneumonia, respectively. The baseline values (before the home-based PR program) were: age $65 \pm 9$ years, FVC $75 \pm 13 \%$ predicted, $\mathrm{FEV}_{1} 73 \pm 12 \%$ predicted, and DLCO $40 \pm 8 \%$ predicted (means \pm standard deviations). Eleven subjects selected the local facility maintenance program (APA group) and 8 preferred to continue exercising at home (control group) (Figure 1). Table 1 shows the outcome measures after 6 months for the whole group, APA group, and control group. For all patients, the beneficial effects of the 8-week PR program on exercise tolerance (6MST), dyspnea, and motivation (introjected regulation) remained significantly improved after 6 months. Strikingly, these findings were driven largely by the gains in the APA group compared with the control group, as indicated by the much higher proportion of subjects in the APA group who reached at least minimal clinically important differences (MCIDs) in these outcomes at 6 months. For example, the APA group showed an improvement of 47 meters in the 6MWT at 6 months compared with the start of the PR program and $73 \%$ of the group improved by at least the MCID for this test. In contrast, the control group showed a decrease of 29 meters at the 6-month point, and only $13 \%$ achieved a $\geq$ MCID improvement.

Several factors may have influenced the differential benefits of the maintenance program between the APA and control groups in the present study. First, continued regular 
exercise appears to be the most crucial aspect of the improvement; thus, all patients in the APA group but only 2 of 8 in the control group reported that they exercised regularly at the local facility and/or at home over the 6 months. These findings are consistent with the recent report by Sharp et al. that nearly half of patients with interstitial lung disease who participated in a PR program failed to continue exercising at home, and these subjects were more likely to lose the benefits of PR after 6 months than the group who continued to exercise [3]. Second, subjects in the APA group were younger $(61 \pm 10$ years vs. $70 \pm 6, p=0.03)$ and had better identified $(2.9 \pm 0.7 v s .2 .3 \pm 0.8, \mathrm{p}=0.04)$ and intrinsic $(2.7 \pm 0.9$ vs. $1.8 \pm 1.0, \mathrm{p}=0.05)$ regulation scores to engage in physical activity compared with the control group. In a previous study of patients with chronic obstructive pulmonary disease (COPD) [6], the APA group was similarly better able to sustain the benefits of PR compared with the control group [6]. In another study, perception of old age and self-determined motivation were found to be a barrier and an enabling factor, respectively, for physical activity [7]. Third, the control group seems had achieved smaller short-term benefits than the APA group, as reflected by the lower proportion of subjects who reached the MCID at the end of PR for the 6MWD (25\% vs. 64\%), the numbers of strokes during the 6MST (38\% vs. $82 \%)$ and the TDI score (38\% vs. 55\%). This which may have discouraged them from continuing with a structured exercise program thereafter. However, this remains speculative because the subjects chose whether to continue with a home-based or local facility-based maintenance program before the end-PR evaluation. Although the lack of randomization is a limitation to our study, it is crucial that patients are offered a choice of physical activity that they enjoy if they are to succeed in a post-PR exercise program. A solution to this problem remains to be found for older subjects and those with low interest in continuing physical activity

Personalized maintenance programs should ideally include contributions not only from PR professionals but also from the patient. Therefore, we should consider allowing the needs, 
preferences, and living environment of each patient to negotiate the design of a follow-up program, rather than funneling all patients into a single 'one size fits all' maintenance program. 


\begin{tabular}{|c|c|c|c|c|c|c|c|c|}
\hline & \multicolumn{4}{|c|}{ All patients $(n=19)$} & \multicolumn{2}{|c|}{$\begin{array}{c}\text { APA group } \\
(\mathbf{n}=11)\end{array}$} & \multicolumn{2}{|c|}{$\begin{array}{l}\text { Control group } \\
\qquad(\mathrm{n}=8)\end{array}$} \\
\hline & Pre-PR & End-PR & 6-months & $\begin{array}{c}\text { P value } \\
\text { (ANOVA) }\end{array}$ & $\begin{array}{c}\text { Change in } \\
\text { outcome } \\
\text { baseline to } 6 \\
\text { months } \\
\text { [CI } 90 \%] \\
\end{array}$ & $\begin{array}{c}\% \text { of } \\
\text { patients } \\
\text { achieving } \\
\text { MCID }\end{array}$ & $\begin{array}{c}\text { Change in } \\
\text { outcome } \\
\text { baseline to } 6 \\
\text { months } \\
\text { [CI } 90 \%] \\
\end{array}$ & $\begin{array}{c}\% \text { of } \\
\text { patients } \\
\text { achieving } \\
\text { MCID }\end{array}$ \\
\hline \multicolumn{9}{|l|}{ Exercise capacity } \\
\hline 6MWT, m & $425 \pm 57$ & $448 \pm 68$ & $440 \pm 87$ & 0.14 & $47[-32: 127]$ & $73 \%$ & $-29[-143: 84]$ & $13 \%$ \\
\hline 6MST, strokes & $494 \pm 135$ & $602 \pm 160^{*}$ & $584 \pm 174^{*}$ & $<0.01$ & $141[-223: 506]$ & $82 \%$ & $29[-141: 199]$ & $38 \%$ \\
\hline \multicolumn{9}{|l|}{ Dyspnea } \\
\hline BDI/TDI, score & $7 \pm 2$ & $0.9 \pm 1.3$ & $1.1 \pm 2.9 *$ & $<0.01$ & $2.6[-0.7: 5.9]$ & $91 \%$ & $-1.1[-6.9: 4.7]$ & $25 \%$ \\
\hline \multicolumn{9}{|l|}{ Quality of life (SF-36) } \\
\hline Physical summary, score & $54 \pm 19$ & $60 \pm 18$ & $58 \pm 23$ & 0.43 & $8[-19: 35]$ & & $-1[-42: 41]$ & \\
\hline Mental summary, score & $60 \pm 21$ & $66 \pm 21$ & $65 \pm 21$ & 0.50 & $12[-24: 55]$ & & $-10[-69: 48]$ & \\
\hline \multicolumn{9}{|c|}{ Motivation regulation (BREQ-2) } \\
\hline Amotivation, score & $0.7 \pm 0.9$ & $0.5 \pm 0.7$ & $0.4 \pm 0.6$ & 0.06 & $-0.1[-1.8: 1.7]$ & & $-0.6[-1.9: 0.7]$ & \\
\hline Extrinsic regulation, score & $1.0 \pm 1.1$ & $0.7 \pm 0.9$ & $0.8 \pm 0.9$ & 0.71 & $-0.1[-2.8: 2.5]$ & & $-0.3[-2.4: 1.9]$ & \\
\hline Introjected regulation, score & $0.7 \pm 0.7$ & $1.4 \pm 0.9 *$ & $1.4 \pm 1.2 *$ & $<0.05$ & $0.7[-1.0: 2.6]$ & & $0.5[-2.4: 3.6]$ & \\
\hline Identified regulation, score & $2.6 \pm 0.8$ & $2.7 \pm 0.6$ & $2.9 \pm 0.8$ & 0.41 & $0.3[-1.0: 1.6]$ & & $0.1[-0.9: 1.2]$ & \\
\hline Intrinsic regulation, score & $2.3 \pm 1.0$ & $2.8 \pm 0.8$ & $2.7 \pm 1.1$ & 0.09 & $0.6[-1.3: 2.5]$ & & $0.2[-1.7: 2.2]$ & \\
\hline
\end{tabular}

*p<0.05 vs. pre-PR value. 6MST, 6-minute stepper test; 6MWT, 6-minute walk test; BDI/TDI, baseline and transition dyspnea indexes; BREQ-2, Behavioural Regulation and Exercise Questionnaire 2; CI, confidence intervals. MCID, minimal clinically important difference; PR, pulmonary rehabilitation; SF-36, Medical Outcomes Study Short Form-36. MCIDs were $30 \mathrm{~m}$ for the 6MWD [8], 40 strokes for the 6MST [9], and 1 point for the TDI [10]. 


\section{Acknowledgments}

We would like to thank the rehabilitation team ( $\mathrm{G}$ Tywoniuk, $\mathrm{S}$ Duriez, F Urbain, V Wauquier, M Grosbois and M Lambinet) and the staff of the Competence Centre for Rare Pulmonary Diseases for managing the patients during the home-based PR and post-PR maintenance programs. We also thank the local facilities (e.g. Cap'Air, Passportsanté, Curves) for their support during the maintenance program. We thank Adair, France Oxygène, Homeperf, LVL, Orkyn, Santélys, SOS Oxygène, Sysmed, VitalAire, and the ARS Hauts-deFrance for financial support of the home-based PR program, the Unite de Recherche Pluridisciplinaire Sport Santé Société (to Pr S Berthoin and J Gamain) for financial support of the 6-month maintenance program. Finally, we thank M Tarrant for English language correction of the manuscript and the authors also wish to thank Anne M. O'Rourke for editing a version of the manuscript. 


\section{References}

1. Wallaert B, Duthoit L, Drumez E, Béhal H, Wemeau L, Chenivesse C et al. Long-term evaluation of home-based pulmonary rehabilitation in patients with fibrotic idiopathic interstitial pneumonias. ERJ Open Res. 2019 Apr 8;5(2). https://doi.org/10.1183/23120541.00045-2019.

2. Cheng L, Tan B, Yin Y, Wang S, Jia L, Warner G et al. Short- and long-term effects of pulmonary rehabilitation for idiopathic pulmonary fibrosis: a systematic review and meta-analysis. Clin Rehabil 2018; 32(10):1299-307. https://doi.org/10.1177/0269215518779122.

3. Sharp C, McCabe M, Hussain MJ, Dodd JW, Lamb H, Adamali H et al. Duration of benefit following completion of pulmonary rehabilitation in interstitial lung disease-an observational study. QJM 2017; 110: 17-22. https://doi.org/10.1093/qjmed/hcw105.

4. Chéhère B, Bougault V, Chenivesse C, Grosbois J-M, Wallaert B. Cardiorespiratory adaptation in a 6-minute walk test by fibrotic idiopathic interstitial pneumonia patients who did or did not respond to pulmonary rehabilitation. Eur J Phys Rehabil Med 2019; 55(1):103-12. https://doi.org/10.23736/S1973-9087.18.05093-1.

5. Markland D, Tobin V. A Modification to the Behavioural Regulation in Exercise Questionnaire to Include an Assessment of Amotivation. Journal of Sport and Exercise Psychology 2004; 26: 191-6.

6. Moullec G, Ninot G, Varray A, Desplan J, Hayot M, Prefaut C. An innovative maintenance follow-up program after a first inpatient pulmonary rehabilitation. Respir Med 2008; 102: 556-66. https://doi.org/10.1016/j.rmed.2007.11.012.

7. Kosteli M-C, Heneghan NR, Roskell C, Williams SE, Adab P, Dickens AP et al. Barriers and enablers of physical activity engagement for patients with COPD in primary care. Int $J$ Chron Obstruct Pulmon Dis 2017; 12: 1019-31. https://doi.org/10.2147/COPD.S119806.

8. Holland AE, Hill CJ, Conron M, Munro P, McDonald CF. Small changes in six-minute walk distance are important in diffuse parenchymal lung disease. Respir Med 2009; 103 : 1430-1435. https://doi.org/10.1016/j.rmed.2009.04.024.

9. Pichon R, Couturaud F, Mialon P, Le Ber-Moy C, Péran L, Lochon C et al. Responsiveness and Minimally Important Difference of the 6-Minute Stepper Test in Patients with Chronic Obstructive Pulmonary Disease. Respiration 2016; 91: 367-373. https://doi.org/10.1159/000446517.

10. Mahler DA, Witek TJ. The MCID of the transition dyspnea index is a total score of one unit. COPD 2005; 2: 99-103. https://doi.org/10.1081/COPD-200050666. 


\section{Figure legend}

Figure 1. Study design.

APA, adapted physical activity; DLCO, diffusing capacity of the lungs for carbon monoxide;

FVC, forced vital capacity; f-NSIP, fibrotic nonspecific interstitial pneumonia; IPF, idiopathic pulmonary fibrosis; $\mathrm{PR}$, pulmonary rehabilitation; $\mathrm{SpO}_{2}$, pulse $\mathrm{O}_{2}$ saturation. 